\title{
Analysis of bone architecture sensitivity for changes in mechanical loading, cellular activity, mechanotransduction, and tissue properties
}

\author{
L. G. E. Cox - B. van Rietbergen • \\ C. C. van Donkelaar • K. Ito
}

Received: 1 April 2010 / Accepted: 19 October 2010 / Published online: 5 November 2010

(C) The Author(s) 2010. This article is published with open access at Springerlink.com

\begin{abstract}
Bone has an architecture which is optimized for its mechanical environment. In various conditions, this architecture is altered, and the underlying cause for this change is not always known. In the present paper, we investigated the sensitivity of the bone microarchitecture for four factors: changes in bone cellular activity, changes in mechanical loading, changes in mechanotransduction, and changes in mechanical tissue properties. The goal was to evaluate whether these factors can be the cause of typical bone structural changes seen in various pathologies. For this purpose, we used an established computational model for the simulation of bone adaptation. We performed two sensitivity analyses to evaluate the effect of the four factors on the trabecular structure, in both developing and adult bone. According to our simulations, alterations in mechanical load, bone cellular activities, mechanotransduction, and mechanical tissue properties may all result in bone structural changes similar to those observed in various pathologies. For example, our simulations confirmed that decreases in loading and increases in osteoclast number and activity may lead to osteoporotic changes. In addition, they showed that both increased loading and decreased bone matrix stiffness may lead to bone structural changes similar to those seen in osteoarthritis. Finally, we found that the model may help in gaining a better understanding of the contribution of individual
\end{abstract}

L. G. E. Cox · C. C. van Donkelaar · K. Ito

Department of Biomedical Engineering, Eindhoven University of Technology, P.O. Box 513, 5600 MB Eindhoven,

The Netherlands

B. van Rietbergen $(\varangle)$

Department of Biomedical Engineering, Eindhoven University of Technology, P.O. Box 513, WH 4.128, 5600 MB Eindhoven, The Netherlands

e-mail: b.v.rietbergen@tue.nl disturbances to a complicated multi-factorial disease process, such as osteogenesis imperfecta.

Keywords Bone architecture - Bone disease . Bone remodeling simulation $\cdot$ Sensitivity analysis

\section{Introduction}

Bones efficiently adapt to changes in mechanical loading, thereby ensuring that bone density is high at load-bearing regions and low at locations of low load. During this continuous adaptation process, bone tissue is resorbed by osteoclasts, and new bone tissue is formed by osteoblasts. It is generally believed that bone adaptation is controlled by osteocytes, which act as mechanosensors and regulate osteoblast and osteoclast activity (Cowin et al. 1991; Lanyon 1993; Klein-Nulend et al. 2003). Osteoyctes are the most abundant cell type of bone, and cell culture studies have demonstrated that they are sensitive to mechanical loading and fluid flow (Klein-Nulend et al. 1995; Mullender et al. 2004). Furthermore, osteocytes form an extensive network by gap-junction connections to each other, lining cells, and osteoblasts (Klein-Nulend et al. 2003; Bonewald 2006), which makes them suitable for their mechanoregulating function.

Several conditions can lead to alteration in the bone architecture. The most common is osteoporosis, in which bone loss typically occurs as the result of hormonal changes or disuse, thereby leading to an increased fracture risk. In addition, bone disorders such as Paget's disease, osteogenesis imperfecta, and osteopetrosis are known to affect the bone tissue properties and induce bone structural changes. Finally, osteoarthritis, which is mainly known for affecting the cartilage, also affects the bone structure and tissue properties. For some of these conditions, it is likely that the changes in the bone 
architecture are predominantly the result of disturbances in the bone remodeling process. These disturbances can be altered osteoblast or osteoclast activity, but also changes in mechanosensitivity of the osteocytes, an affected mechanotransduction pathway, or a combination of these factors. In other cases however, the bone structural changes are likely the result of a normal load adaptation process in response to altered mechanical loading or altered mechanical bone matrix properties.

In the present paper, we grouped these possible causes for alteration in the bone architecture into four factors: changes in bone cellular activity, changes in mechanical loading, changes in mechanotransduction, and changes in mechanical tissue properties. The goal of this study was to investigate the sensitivity of the bone microarchitecture for each of these factors, thus to investigate whether typical bone structural changes seen in various conditions can be explained by one or more of these factors. For this purpose, we used a well established computational model for the simulation of bone adaptation, developed by Huiskes et al. (2000). This model incorporates the individual actions of the different bone cell types (osteoclasts, osteoblasts, and osteocytes). The osteocytes are assumed to react to the local loading conditions by promoting osteoblastic bone formation, and the model thus incorporates osteocyte mechanosensitivity and mechanotransduction (Huiskes et al. 2000; Ruimerman et al. 2001, 2005).

The four factors mentioned above were represented by parameter changes in the bone adaptation model. We systematically investigated the effects of these factors on the bone architecture as predicted by the model, by performing a sensitivity analysis. For most of these factors, more than one parameter was included, leading to a variation in a total of 13 model parameters. As representatives of model outcome, we chose bone density, trabecular thickness, trabecular number, and trabecular separation, because these parameters are frequently used to characterize bone structure, and they are important determinants of bone strength (Liu et al. 2006). Where possible, we validated the effects of model parameter variations against experimental data from the literature.

\section{Methods}

2.1 Mathematical description of the bone remodeling theory

Figure 1 is a schematic representation of the bone remodeling theory (Huiskes et al. 2000).

Each osteocyte produces a stimulus $P$ in response to the local strain energy density (SED) rate. At each location $x$ on the bone surface, the total osteocyte stimulus $P(x, t)$ is

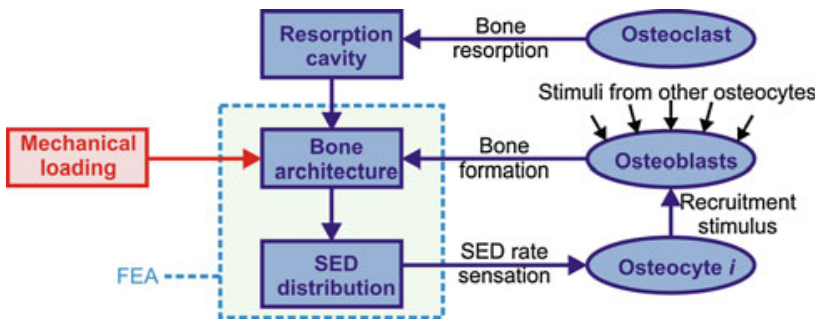

Fig. 1 Schematic representation of the bone remodeling theory

calculated by summation of the stimuli of the surrounding osteocytes:

$P(x, t)=\sum_{k=1}^{n} f\left(x, x_{k}\right) \mu U\left(x_{k}, t\right)$.

Here, $U\left(x_{k}, t\right)$ is the SED rate at the location of osteocyte $k, n$ is the total number of osteocytes within the influence distance of $x, \mu$ is the osteocyte mechanosensitivity, and $f\left(x, x_{k}\right)$ is a signal decay function:

$f\left(x, x_{k}\right)=\mathrm{e}^{\frac{-d\left(x, x_{k}\right)}{D}}$,

depending on the distance between osteocyte $k$ and location $x$ on the bone surface $d\left(x, x_{k}\right)$, and decay parameter $D$. If the total osteocyte stimulus $P(x, t)$ exceeds formation threshold $k_{\text {thr }}$, bone is formed according to:

$\frac{\mathrm{d} V_{f}(x, t)}{\mathrm{d} t}=\tau\left(P(x, t)-k_{\mathrm{thr}}\right) \quad$ if $P(x, t)>k_{\mathrm{thr}}$.

Here, $\frac{\mathrm{d} V_{f}(x, t)}{\mathrm{d} t}$ is the change in bone volume at location $x$ due to bone formation, and $\tau$ is a time constant related to the rate of bone formation. Resorption is assumed to be triggered by randomly occurring microcracks. Therefore, the resorption chance is equal for all locations on the bone surface, determined by the frequency at which new resorption pits are formed, $F_{\text {res }}$. Furthermore, at each location where resorption occurs, the same amount of tissue $V_{\mathrm{cl}}$ is resorbed.

$\frac{\mathrm{d} V_{r}(x, t)}{\mathrm{d} t}=-V_{\mathrm{cl}}$

The total change in bone volume becomes:

$\frac{\mathrm{d} V(x, t)}{\mathrm{d} t}=\frac{\mathrm{d} V_{f}(x, t)}{\mathrm{d} t}+\frac{\mathrm{d} V_{r}(x, t)}{\mathrm{d} t}$

With this volume change, the local relative bone density $\rho(x, t)$ (ranging between 0 and 1 ) can be calculated, which influences the elastic modulus of the tissue $E(x, t)$ according to:

$E(x, t)=E_{b} \rho(x, t)^{\gamma}$.

Here, $E_{b}$ is the elastic modulus of bone tissue and $\gamma$ is a material constant. 
Table 1 Model parameters

\begin{tabular}{|c|c|c|c|c|c|}
\hline Factor & Symbol & Variable & Value & Unit & Reference \\
\hline \multirow[t]{4}{*}{ Bone cellular activity } & $\tau$ & Formation time constant & $9.1 \times 10^{-4}$ & $\mathrm{~mm}^{5} \mathrm{nmol}^{-1}$ & \\
\hline & $V_{\mathrm{cl}}$ & Resorption space & $1.5 \times 10^{-3}$ & $\mathrm{~mm}^{2} \mathrm{~h}^{-1}$ & $a, b$ \\
\hline & $F_{\text {res }}$ & Resorption frequency & 12.8 & $\mathrm{~mm}^{-2} \mathrm{~h}^{-1}$ & \\
\hline & $n$ & Osteocyte density & 1,600 & $\mathrm{~mm}^{-2}$ & $\mathrm{c}$ \\
\hline \multirow[t]{3}{*}{ Mechano-transduction } & $D$ & Osteocyte decay parameter & 0.1 & $\mathrm{~mm}$ & $\mathrm{~d}$ \\
\hline & $\mu$ & Osteocyte mechanosensitivity & 0.5 & $\mathrm{nmol} \mathrm{mm} \mathrm{J} \mathrm{J}^{-1} \mathrm{~h}^{-1}$ & \\
\hline & $k_{\mathrm{thr}}$ & Formation threshold & $2.0 \times 10^{-4}$ & 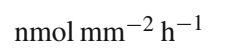 & \\
\hline \multirow[t]{5}{*}{ Mechanical tissue properties } & $E_{b}$ & Elastic modulus bone & $5 \times 10^{3}$ & $\mathrm{MPa}$ & $\mathrm{e}, \mathrm{f}, \mathrm{g}$ \\
\hline & $v_{b}$ & Poisson ratio bone & 0.3 & - & $h, i$ \\
\hline & $E_{m}$ & Elastic modulus marrow & 1 & $\mathrm{MPa}$ & \\
\hline & $v_{m}$ & Poisson ratio marrow & 0.3 & - & \\
\hline & $\gamma$ & Bone material constant & 3.0 & - & $\mathrm{j}$ \\
\hline
\end{tabular}

${ }^{a}$ Eriksen and Kassem (1992)

${ }^{b}$ Parfitt (1994)

${ }^{c}$ Marotti et al. (1990)

${ }^{d}$ Mullender and Huiskes (1995)

e Rho et al. (1993)

${ }^{\mathrm{f}}$ Choi et al. (1990)

$\mathrm{g}$ van Rietbergen et al. (1995)

${ }^{\mathrm{h}}$ Rho (1996)

${ }^{\mathrm{i}}$ Ashman et al. (1984)

j Currey (1988)

\subsubsection{D FEA model}

We evaluated the effects of model parameter variation in a $2 \mathrm{D}$ domain. We used a square mesh of $5 \mathrm{~mm}^{2}$, with an element size of $50 \times 50 \mu \mathrm{m}$. The mesh was loaded statically with $1.5 \mathrm{MPa}$ compression in both horizontal and vertical directions (perpendicular to the mesh), which for a linear elastic material represents the maximum SED rate of a dynamic load of $0.75 \mathrm{MPa}$ at $1 \mathrm{~Hz}$ (Ruimerman et al. 2001). This external force $F$ was varied to represent changes in mechanical load. Although literature data on stresses in cancellous bone tissue vary (Heijink et al. 2008; Jonkers et al. 2008), the load we used is reasonable for human cancellous bone.

\subsubsection{Model parameters}

As we evaluated the model in a $2 \mathrm{D}$ domain, all parameters are related to area rather than volume (Table 1). Parameters related to bone cellular activity are bone formation time constant $\tau$, resorption space $V_{\mathrm{cl}}$, resorption frequency $F_{\text {res }}$, and osteocyte density $n$. Mechanotransduction parameters are signal decay parameter $D$ that represents the osteocyte influence distance, osteocyte mechanosensitivity $\mu$, and bone formation threshold $k_{\mathrm{thr}}$. Mechanical tissue parameters are the elastic modulus and poisson ratio of both bone and bone marrow $\left(E_{b}, E_{m}, v_{b}\right.$ and $\left.v_{m}\right)$, and bone material parameter $\gamma$.

$V_{\mathrm{cl}}$ was derived from two experimental studies. Eriksen and Kassem (1992) found that trabecular BMUs have a length of $100 \mu \mathrm{m}$ and a thickness between 40 and $70 \mu \mathrm{m}$. Assuming that trabecular BMUs are approximately shaped as half a cylinder and that the length axis of a BMU runs parallel to the length axis of a trabecula, this leads to an average $2 \mathrm{D}$ cross-sectional area (depending on the location of sectioning) between $3.1 \times 10^{-3}$ and $5.5 \times 10^{-3} \mathrm{~mm}^{2}$. According to Parfitt (1994), the resorption cavity in cancellous bone is approximately $30 \%$ of the BMU size, leading to a resorption area of $0.9 \times 10^{-3}-1.6 \times 10^{-3} \mathrm{~mm}^{2} . n$ was chosen within the osteocyte lacunae density range found for various species (Marotti et al. 1990). $D$ was set in agreement with a simulation study (Mullender and Huiskes 1995). $E_{b}$ and $v_{b}$ were chosen within the range of experimental values found in literature (Rho et al. 1993; Rho 1996; Choi et al. 1990; van Rietbergen et al. 1995; Ashman et al. 1984). For the bone marrow, no data could be found in literature, so values from previous simulation studies were used (Ruimerman et al. 2005). $\gamma$ was derived from experimental data (Currey 1988). $\mu, k_{\mathrm{thr}}, \tau$, and $F_{\text {res }}$, could not be derived from literature. Their values were chosen such that an equilibrium bone turnover rate of approximately $17 \%$ per year was obtained, in agreement with literature data (Han et al. 1997). 

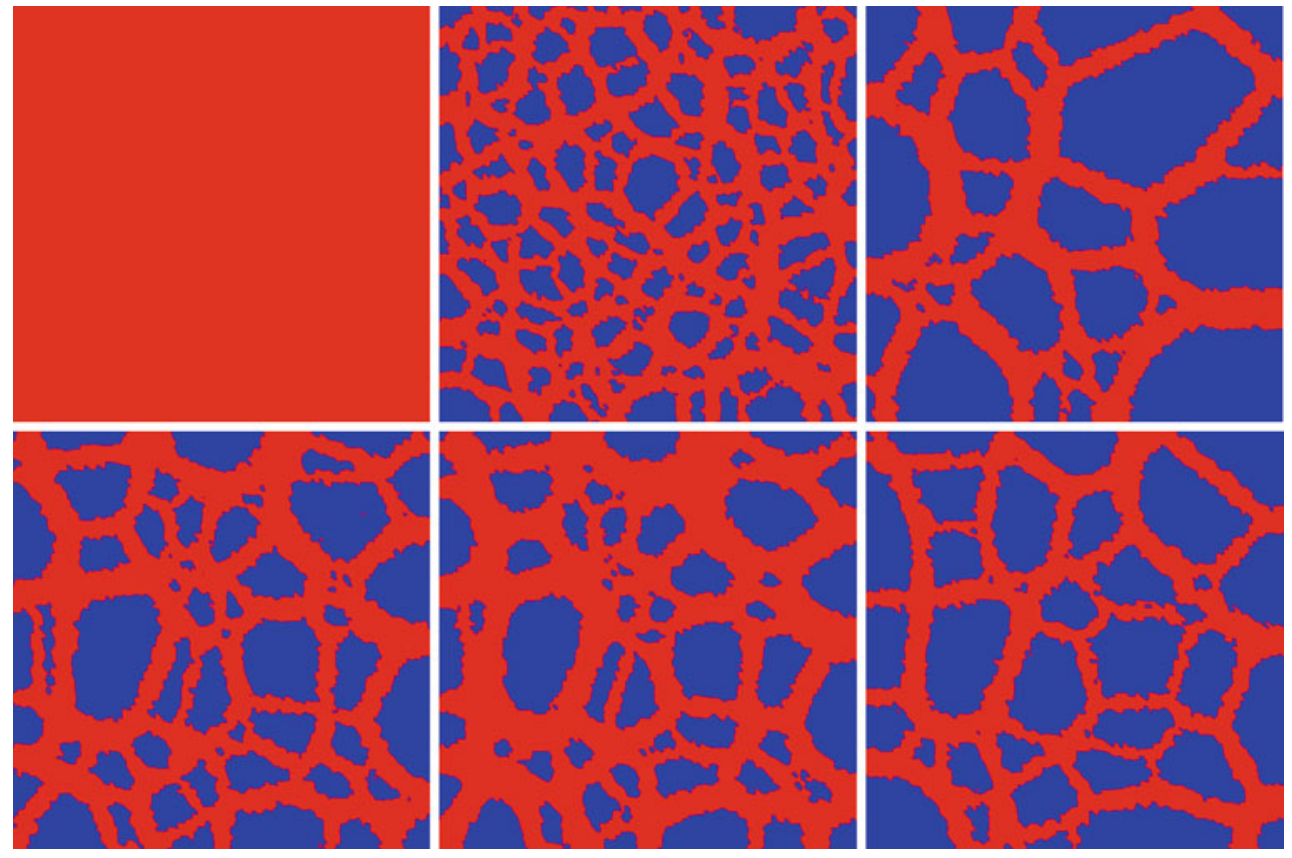

Fig. 2 Bone structures; Top from left to right the starting point for all simulations of analysis 1 , the result of simulation 4 of analysis 1 , and the result of simulation 19 of analysis 1 . Bottom, from left to right: the starting point for all simulations of analysis 2 , the result of simulation 4 of analysis 2 , and the result of simulation 19 of analysis 2

\subsubsection{Bone structure parameters}

To evaluate the effect of model parameter variations, we determined structure parameters from the simulated bone architectures. Bone density was determined by dividing the area of bone by the total area, and trabecular number by counting the trabecular intersections along each horizontal pixel row. Trabecular thickness was defined for each trabecular surface pixel as the smallest distance to another trabecular surface pixel, bordering a different marrow cavity. Trabecular separation was defined for each marrow cavity as the largest distance between two bone surface pixels bordering the marrow cavity.

\subsection{Taguchi sensitivity analyses (Logothetis and Wynn 1989)}

We separated our study into two sensitivity analyses; first, we looked at the effects of parameter variations on the development of a trabecular structure from a uniform density, and secondly we investigated the effects of parameter variations on the remodeling of an existing trabecular structure. The first analysis represents the effect of the four factors when they are already present during growth, while the second analysis represents the effect of the four factors when they occur after the development of a mature trabecular structure. For all simulations in the second analysis, the resulting structure of

the baseline simulation of the first analysis was used as starting point (Fig. 2). We performed 3-level, fractional factorial Taguchi sensitivity analyses, based on orthogonal array (OA) designs. In every pair of columns of an orthogonal array, each combination of levels appears the same number of times, guaranteeing that the averaged effect of each parameter can be determined while the levels of all other parameters are varied. This type of fractional design dramatically reduces the number of simulations.

We performed $\mathrm{OA}_{27}\left(3^{13}\right)$ analyses, meaning that for both sensitivity analyses, 27 simulations were used for a 3-level evaluation of 13 parameters. The 3-level analysis enables the differentiation between a quadratic and a linear effect of model parameters. We chose to vary all parameters between a low level that was $85 \%$ of the standard value, a normal level (standard value, see Table 1), and a high level that was $115 \%$ of the standard value. Table 2 shows the overview of the parameter levels of the 27 simulations that we performed for both sensitivity analyses.

From the simulation results, the correction factor $(C F)$ and corrected total sum of squares (TSS) for each structure parameter were calculated, according to:

$$
\begin{aligned}
& C F=\frac{\left(\sum_{i=1}^{n} Y_{i}\right)^{2}}{n} \\
& T S S=\sum_{i=1}^{n} Y_{i}^{2}-C F
\end{aligned}
$$


Table 2 Taguchi table, showing the different levels of the parameter values for each of the 27 simulations

\begin{tabular}{|c|c|c|c|c|c|c|c|c|c|c|c|c|c|}
\hline & $n$ & $D$ & $V_{\mathrm{cl}}$ & $\gamma$ & $\mu$ & $k_{\mathrm{thr}}$ & $\tau$ & $F_{\text {res }}$ & $E_{b}$ & $v_{b}$ & $E_{m}$ & $v_{m}$ & $F$ \\
\hline 1 & $\mathrm{~m}$ & $\mathrm{~m}$ & $\mathrm{~m}$ & $\mathrm{~m}$ & $\mathrm{~m}$ & $\mathrm{~m}$ & $\mathrm{~m}$ & $\mathrm{~m}$ & $\mathrm{~m}$ & $\mathrm{~m}$ & $\mathrm{~m}$ & $\mathrm{~m}$ & $\mathrm{~m}$ \\
\hline 2 & $\mathrm{~m}$ & $\mathrm{~m}$ & $\mathrm{~m}$ & $\mathrm{~m}$ & 1 & 1 & 1 & 1 & 1 & 1 & 1 & 1 & 1 \\
\hline 3 & $\mathrm{~m}$ & $\mathrm{~m}$ & $\mathrm{~m}$ & $\mathrm{~m}$ & $\mathrm{~h}$ & $\mathrm{~h}$ & $\mathrm{~h}$ & $\mathrm{~h}$ & 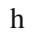 & $\mathrm{h}$ & $\mathrm{h}$ & 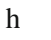 & $\mathrm{h}$ \\
\hline 4 & $\mathrm{~m}$ & 1 & 1 & 1 & $\mathrm{~m}$ & $\mathrm{~m}$ & $\mathrm{~m}$ & 1 & 1 & 1 & $\mathrm{~h}$ & $\mathrm{~h}$ & $\mathrm{~h}$ \\
\hline 5 & $\mathrm{~m}$ & 1 & 1 & 1 & 1 & 1 & 1 & $\mathrm{~h}$ & 11 & $\mathrm{~h}$ & $\mathrm{~m}$ & $\mathrm{~m}$ & $\mathrm{~m}$ \\
\hline 6 & $\mathrm{~m}$ & 1 & 1 & 1 & $\mathrm{~h}$ & $\mathrm{~h}$ & $\mathrm{~h}$ & $\mathrm{~m}$ & $\mathrm{~m}$ & $\mathrm{~m}$ & 1 & 1 & 1 \\
\hline 7 & $\mathrm{~m}$ & $\mathrm{~h}$ & $\mathrm{~h}$ & $\mathrm{~h}$ & $\mathrm{~m}$ & $\mathrm{~m}$ & $\mathrm{~m}$ & $\mathrm{~h}$ & $\mathrm{~h}$ & $\mathrm{~h}$ & 1 & 1 & 1 \\
\hline 8 & $\mathrm{~m}$ & $\mathrm{~h}$ & $\mathrm{~h}$ & $\mathrm{~h}$ & 1 & 1 & 1 & $\mathrm{~m}$ & $\mathrm{~m}$ & $\mathrm{~m}$ & $\mathrm{~h}$ & $\mathrm{~h}$ & $\mathrm{~h}$ \\
\hline 9 & $\mathrm{~m}$ & $\mathrm{~h}$ & $\mathrm{~h}$ & $\mathrm{~h}$ & $\mathrm{~h}$ & $\mathrm{~h}$ & $\mathrm{~h}$ & 1 & 1 & 1 & $\mathrm{~m}$ & $\mathrm{~m}$ & $\mathrm{~m}$ \\
\hline 10 & 1 & $\mathrm{~m}$ & 1 & $\mathrm{~h}$ & $\mathrm{~m}$ & 1 & $\mathrm{~h}$ & $\mathrm{~m}$ & 1 & $\mathrm{~h}$ & $\mathrm{~m}$ & 1 & $\mathrm{~h}$ \\
\hline 11 & 1 & $\mathrm{~m}$ & 1 & $\mathrm{~h}$ & 1 & $\mathrm{~h}$ & $\mathrm{~m}$ & 1 & $\mathrm{~h}$ & $\mathrm{~m}$ & 1 & $\mathrm{~h}$ & $\mathrm{~m}$ \\
\hline 12 & 1 & $\mathrm{~m}$ & 1 & $\mathrm{~h}$ & $\mathrm{~h}$ & $\mathrm{~m}$ & 1 & $\mathrm{~h}$ & $\mathrm{~m}$ & 1 & $\mathrm{~h}$ & $\mathrm{~m}$ & 1 \\
\hline 13 & 1 & 1 & $\mathrm{~h}$ & $\mathrm{~m}$ & $\mathrm{~m}$ & 1 & $\mathrm{~h}$ & 1 & 11 & $\mathrm{~m}$ & $\mathrm{~h}$ & $\mathrm{~m}$ & 1 \\
\hline 14 & 1 & 1 & $\mathrm{~h}$ & $\mathrm{~m}$ & 1 & $\mathrm{~h}$ & $\mathrm{~m}$ & $\mathrm{~h}$ & $\mathrm{~m}$ & 1 & $\mathrm{~m}$ & 1 & $\mathrm{~h}$ \\
\hline 15 & 1 & 1 & $\mathrm{~h}$ & $\mathrm{~m}$ & $\mathrm{~h}$ & $\mathrm{~m}$ & 1 & $\mathrm{~m}$ & 1 & $\mathrm{~h}$ & 1 & $\mathrm{~h}$ & $\mathrm{~m}$ \\
\hline 16 & 1 & $\mathrm{~h}$ & $\mathrm{~m}$ & 1 & $\mathrm{~m}$ & 1 & $\mathrm{~h}$ & $\mathrm{~h}$ & $\mathrm{~m}$ & 1 & 1 & $\mathrm{~h}$ & $\mathrm{~m}$ \\
\hline 17 & 1 & $\mathrm{~h}$ & $\mathrm{~m}$ & 1 & 1 & $\mathrm{~h}$ & $\mathrm{~m}$ & $\mathrm{~m}$ & 1 & $\mathrm{~h}$ & $\mathrm{~h}$ & $\mathrm{~m}$ & 1 \\
\hline 18 & 1 & $\mathrm{~h}$ & $\mathrm{~m}$ & 1 & $\mathrm{~h}$ & $\mathrm{~m}$ & 1 & 1 & $\mathrm{~h}$ & $\mathrm{~m}$ & $\mathrm{~m}$ & 1 & $\mathrm{~h}$ \\
\hline 19 & $\mathrm{~h}$ & $\mathrm{~m}$ & $\mathrm{~h}$ & 1 & $\mathrm{~m}$ & $\mathrm{~h}$ & 1 & $\mathrm{~m}$ & $\mathrm{~h}$ & 1 & $\mathrm{~m}$ & $\mathrm{~h}$ & 1 \\
\hline 20 & $\mathrm{~h}$ & $\mathrm{~m}$ & $\mathrm{~h}$ & 1 & 1 & $\mathrm{~m}$ & $\mathrm{~h}$ & 1 & $\mathrm{~m}$ & $\mathrm{~h}$ & 1 & $\mathrm{~m}$ & $\mathrm{~h}$ \\
\hline 21 & $\mathrm{~h}$ & $\mathrm{~m}$ & $\mathrm{~h}$ & 1 & $\mathrm{~h}$ & 1 & $\mathrm{~m}$ & $\mathrm{~h}$ & 1 & $\mathrm{~m}$ & $\mathrm{~h}$ & 1 & $\mathrm{~m}$ \\
\hline 22 & $\mathrm{~h}$ & 1 & $\mathrm{~m}$ & $\mathrm{~h}$ & $\mathrm{~m}$ & $\mathrm{~h}$ & 1 & 1 & $\mathrm{~m}$ & $\mathrm{~h}$ & $\mathrm{~h}$ & 1 & $\mathrm{~m}$ \\
\hline 23 & $\mathrm{~h}$ & 1 & $\mathrm{~m}$ & $\mathrm{~h}$ & 1 & $\mathrm{~m}$ & $\mathrm{~h}$ & $\mathrm{~h}$ & 1 & $\mathrm{~m}$ & $\mathrm{~m}$ & $\mathrm{~h}$ & 1 \\
\hline 24 & $\mathrm{~h}$ & 1 & $\mathrm{~m}$ & $\mathrm{~h}$ & $\mathrm{~h}$ & 1 & $\mathrm{~m}$ & $\mathrm{~m}$ & $\mathrm{~h}$ & 1 & 1 & $\mathrm{~m}$ & $\mathrm{~h}$ \\
\hline 25 & $\mathrm{~h}$ & $\mathrm{~h}$ & 1 & $\mathrm{~m}$ & $\mathrm{~m}$ & $\mathrm{~h}$ & 1 & $\mathrm{~h}$ & 1 & $\mathrm{~m}$ & 1 & $\mathrm{~m}$ & $\mathrm{~h}$ \\
\hline 26 & $\mathrm{~h}$ & $\mathrm{~h}$ & 1 & $\mathrm{~m}$ & 1 & $\mathrm{~m}$ & $\mathrm{~h}$ & $\mathrm{~m}$ & $\mathrm{~h}$ & 1 & $\mathrm{~h}$ & 1 & $\mathrm{~m}$ \\
\hline 27 & $\mathrm{~h}$ & $\mathrm{~h}$ & 1 & $\mathrm{~m}$ & $\mathrm{~h}$ & 1 & $\mathrm{~m}$ & 1 & $\mathrm{~m}$ & $\mathrm{~h}$ & $\mathrm{~m}$ & $\mathrm{~h}$ & 1 \\
\hline
\end{tabular}

1 indicates the low level, $\mathrm{m}$ the middle level, and $\mathrm{h}$ the high level

Here, $n$ is the total number of simulations, and $Y_{i}$ is the structure parameter value of simulation $i$. Subsequently, $S S_{A}$, the sum of squares of the effect of each model parameter $A$, was calculated:

$S S_{A}=\frac{S_{A_{l}}^{2}+S_{A_{m}}^{2}+S_{A_{h}}^{2}}{m}-C F$

Here, $S_{A_{i}}$ is the sum total, where parameter $A$ has level $i$ (ranging from 1-h), and $m$ is the number of observations for each level. Furthermore, we separated the sum of squares of each parameter into a linear $\left(S S_{A, l}\right)$ and a quadratic $\left(S S_{A, q}\right)$ effect:

$$
\begin{aligned}
S S_{A, l} & =\frac{\left(-S_{A_{l}}+S_{A_{h}}\right)^{2}}{2 m} \\
S S_{A, q} & =\frac{\left(S_{A_{l}}-2 S_{A_{m}}+S_{A_{h}}\right)^{2}}{6 m}
\end{aligned}
$$

\section{Results}

First, we determined the number of increments required to obtain an equilibrium with respect to the bone structure, by looking at the change in bone fraction, trabecular thickness, trabecular number, and trabecular separation. Based on this we decided to run all simulations from Table 2 for 1,500 increments for the first sensitivity analysis, and for 1,000 increments for the second analysis, after which the bone structure parameters were determined. Some examples of the resulting trabecular structures are shown in Fig. 2.

\subsection{Bone structure parameters}

The bone structure parameters determined from the 'baseline' simulation are shown in Table 3, together with experimental values from literature. The bone fraction seems rather high, while trabecular number seems low compared to literature values, but an increase in trabecular number would only further increase the bone fraction. The difference between simulation and experimental data can largely be attributed to the fact that in the simulations, all trabeculae are connected in the $2 \mathrm{D}$ plane, whereas this is not the case for 3D bone structures. Since we focus on the change in structure parameters as a result of a variation in model parameters, rather than on the structure parameter values themselves, we conclude that the simulated structure parameters are reasonable. The structure parameters were determined automatically as described in the methods section for all simulations (Table 4).

It can be seen from Table 4 that the bone fractions from the first and second analyses are almost equal for the corresponding simulations, while the other structure parameters are not. In the second analysis, the number of trabeculae is largely determined by the initial bone structure, ensuring that to obtain a similar strength, bone thickness is changed rather than trabecular number. In the model, it is difficult to create new trabeculae in an existing structure, which is why the number of trabeculae either remains at the same level or decreases in comparison with the initial structure in the second analysis. This decrease can be caused by resorption of

Table 3 Bone structure parameters determined from the baseline simulation (simulation 1 of the first analysis)

\begin{tabular}{lll}
\hline & Simulation & Literature $^{\mathrm{a}, \mathrm{b}, \mathrm{c}, \mathrm{d}}$ \\
\hline Bone fraction (BF) & 0.52 & $0.15-0.41$ \\
Trabecular thickness (Tb.Th) & $221 \mu \mathrm{m}$ & $119-330 \mu \mathrm{m}$ \\
Trabecular number (Tb.N) & $1.20 \mathrm{~mm}^{-1}$ & $1.30-1.90 \mathrm{~mm}^{-1}$ \\
Trabecular separation (Tb.Sp) & $656 \mu \mathrm{m}$ & $300-740 \mu \mathrm{m}$ \\
\hline
\end{tabular}

\footnotetext{
${ }^{a}$ Akhter et al. (2007)

${ }^{b}$ Cortet et al. (2004)

${ }^{\mathrm{c}}$ Hildebrand et al. (1999)

${ }^{\mathrm{d}}$ Krug et al. (2008)
} 
Table 4 Taguchi simulation results

\begin{tabular}{|c|c|c|c|c|c|c|c|c|}
\hline & \multicolumn{4}{|c|}{ Analysis 1} & \multicolumn{4}{|c|}{ Analysis 2} \\
\hline & $\mathrm{BF}$ & Tb.Th & Tb.N & Tb.Sp & $\mathrm{BF}$ & Tb.Th & Tb.N & Tb.Sp \\
\hline 1 & 0.52 & 221 & 1.20 & 656 & 0.52 & 221 & 1.20 & 656 \\
\hline 2 & 0.46 & 213 & 1.19 & 779 & 0.46 & 227 & 1.16 & 816 \\
\hline 3 & 0.59 & 211 & 1.37 & 517 & 0.58 & 241 & 1.15 & 619 \\
\hline 4 & 0.61 & 170 & 1.75 & 396 & 0.61 & 255 & 1.07 & 581 \\
\hline 5 & 0.37 & 192 & 1.05 & 877 & 0.37 & 193 & 1.16 & 895 \\
\hline 6 & 0.47 & 175 & 1.40 & 605 & 0.46 & 212 & 1.23 & 778 \\
\hline 7 & 0.42 & 263 & 0.92 & 944 & 0.43 & 230 & 1.08 & 923 \\
\hline 8 & 0.55 & 230 & 1.31 & 646 & 0.54 & 256 & 1.09 & 688 \\
\hline 9 & 0.71 & 201 & 1.49 & 349 & 0.70 & 309 & 0.98 & 515 \\
\hline 10 & 0.66 & 191 & 1.51 & 381 & 0.65 & 307 & 0.99 & 597 \\
\hline 11 & 0.49 & 203 & 1.26 & 611 & 0.49 & 247 & 1.09 & 813 \\
\hline 12 & 0.42 & 218 & 1.06 & 861 & 0.42 & 214 & 1.10 & 925 \\
\hline 13 & 0.37 & 194 & 1.12 & 932 & 0.37 & 196 & 1.07 & 871 \\
\hline 14 & 0.45 & 248 & 1.03 & 986 & 0.39 & 202 & 1.09 & 909 \\
\hline 15 & 0.43 & 192 & 1.19 & 723 & 0.42 & 209 & 1.10 & 890 \\
\hline 16 & 0.55 & 237 & 1.25 & 659 & 0.54 & 245 & 1.14 & 703 \\
\hline 17 & 0.48 & 227 & 1.14 & 760 & 0.47 & 237 & 1.13 & 838 \\
\hline 18 & 0.61 & 219 & 1.38 & 500 & 0.61 & 274 & 1.06 & 646 \\
\hline 19 & 0.38 & 254 & 0.84 & 980 & 0.40 & 224 & 1.06 & 968 \\
\hline 20 & 0.62 & 199 & 1.46 & 468 & 0.61 & 263 & 1.08 & 602 \\
\hline 21 & 0.56 & 227 & 1.25 & 630 & 0.56 & 248 & 1.16 & 694 \\
\hline 22 & 0.48 & 204 & 1.23 & 674 & 0.48 & 212 & 1.21 & 743 \\
\hline 23 & 0.42 & 204 & 1.13 & 822 & 0.41 & 206 & 1.12 & 912 \\
\hline 24 & 0.54 & 197 & 1.38 & 537 & 0.54 & 241 & 1.12 & 697 \\
\hline 25 & 0.69 & 194 & 1.56 & 360 & 0.69 & 311 & 0.96 & 538 \\
\hline 26 & 0.61 & 214 & 1.38 & 472 & 0.61 & 253 & 1.09 & 600 \\
\hline 27 & 0.65 & 188 & 1.61 & 383 & 0.65 & 292 & 1.00 & 585 \\
\hline
\end{tabular}

The calculated structure parameters for each of the 27 simulations of both analyses

trabeculae due to a decrease in trabecular thickness and by fusion of trabeculae due to an increase in trabecular thickness.

\subsection{Statistical analysis}

The correction factors, corrected total sums of squares, and sum totals per level that were calculated for each structure parameter from the results in Table 4 are shown in Tables 5 and 6 . In Table 7, the combined sum of squares, the linear sum of squares, and the quadratic sum of squares for each model parameter with respect to the four different structure parameters are shown, expressed as the percentage of the total sum of squares for that structure parameter. When a combined sum of squares accounts for more than $5 \%$ of the total sum of squares, it is indicated by the use of bold font in Table 7. Table 8 gives an orderly overview of the qualitative
Table 5 Correction factor and corrected total sum of squares

\begin{tabular}{|c|c|c|c|c|}
\hline & \multicolumn{2}{|c|}{ Analysis 1} & \multicolumn{2}{|c|}{ Analysis 2} \\
\hline & $\mathrm{CF}$ & TSS & $\mathrm{CF}$ & TSS \\
\hline $\mathrm{BF}$ & 7.37 & $2.62 \mathrm{e}-1$ & 7.24 & $2.63 \mathrm{e}-1$ \\
\hline Tb.Th & $1.20 \mathrm{e} 6$ & $1.35 \mathrm{e} 4$ & $1.58 \mathrm{e} 6$ & $3.02 \mathrm{e} 4$ \\
\hline Tb.N & $4.40 \mathrm{e} 1$ & 1.17 & $3.26 \mathrm{e} 1$ & $1.18 \mathrm{e}-1$ \\
\hline Tb.Sp & $1.14 \mathrm{e} 7$ & $1.05 \mathrm{e} 6$ & $1.48 \mathrm{e} 7$ & $5.02 \mathrm{e} 5$ \\
\hline
\end{tabular}

effect of individual parameter variations on bone structure parameters.

The corrected total sum of squares for the bone fraction is similar for both sensitivity analyses (Table 5), as was expected from the similarity in bone fractions (Table 4). The corrected total sum of squares for the trabecular thickness and trabecular separation is larger for the second analysis, while the corrected total sum of squares for the trabecular number is higher for the first analysis. This was also expected, since the variation in trabecular number is limited when starting from an initial bone structure, which is why trabecular thickness and separation respond more strongly to parameter variations during remodeling.

\subsubsection{Effects of model parameter variations on bone structure development}

When developing a trabecular structure from a uniform density, the bone fraction is mostly influenced by changes in external load $F$ and osteocyte influence distance $D$ (Table 7). Increases in $F$ and $D$ both lead to a higher bone fraction (Tables 6, 8). Additionally, increases in osteocyte density $n$, formation time constant $\tau$, and osteocyte mechanosensitivity $\mu$ have a markedly positive effect on bone fraction, while increases in resorption space $V_{\mathrm{cl}}$, resorption frequency $F_{\text {res }}$, and $E_{b}$ have a markedly negative effect on bone fraction.

The most influential parameters with respect to trabecular thickness are $V_{\mathrm{cl}}, F_{\text {res }}$, and $D$. Trabecular thickness is negatively related to both $V_{\mathrm{cl}}$ and $F_{\text {res }}$ and positively related to $D$. In addition, trabecular thickness is negatively related to $E_{b}$, and either an increase or decrease in $\tau$ leads to a decrease in trabecular thickness, while increases and decreases in $v_{m}$ have the opposite effect.

Trabecular number is mainly influenced by $F, V_{\mathrm{cl}}$, and $F_{\text {res. }}$. An increase in $F$ leads to more trabeculae, while increases in $V_{\mathrm{cl}}$ and $F_{\text {res }}$ reduce the number of trabeculae. Furthermore, trabecular number is increased by increases in $\tau$ and $\mu$ or a decrease in $E_{b}$.

The main determinant of trabecular separation is $F$, which is linearly inversely related to trabecular separation. $\tau, n, D$, and $\mu$ are also linearly inversely related to trabecular 
Table 6 Sum totals per model parameter for each level ( 1 is low, $\mathrm{m}$ is middle, and $\mathrm{h}$ is high)

\begin{tabular}{|c|c|c|c|c|c|c|c|c|c|c|c|c|c|}
\hline & $F$ & $\tau$ & $V_{\mathrm{cl}}$ & $F_{\text {res }}$ & $n$ & $D$ & $\mu$ & $k_{\mathrm{thr}}$ & $E_{b}$ & $v_{b}$ & $E_{m}$ & $v_{m}$ & $\gamma$ \\
\hline \multicolumn{14}{|c|}{ Analysis 1} \\
\hline \multicolumn{14}{|l|}{$\mathbf{B F}$} \\
\hline$S_{A_{l}}$ & 4.07 & 4.39 & 4.97 & 5.00 & 4.46 & 4.14 & 4.45 & 4.71 & 5.02 & 4.73 & 4.67 & 4.72 & 4.65 \\
\hline$S_{A_{m}}$ & 4.72 & 4.72 & 4.65 & 4.64 & 4.70 & 4.70 & 4.68 & 4.66 & 4.71 & 4.68 & 4.77 & 4.72 & 4.77 \\
\hline$S_{A_{h}}$ & 5.32 & 5.00 & 4.49 & 4.47 & 4.95 & 5.27 & 4.98 & 4.74 & 4.38 & 4.70 & 4.67 & 4.67 & 4.69 \\
\hline \multicolumn{14}{|c|}{ Tb.Th } \\
\hline$S_{A_{l}}$ & 1936 & 1916 & 1745 & 1791 & 1929 & 1776 & 1930 & 1869 & 1819 & 1952 & 1873 & 1954 & 1900 \\
\hline$S_{A_{m}}$ & 1891 & 1944 & 1933 & 1901 & 1876 & 1937 & 1928 & 1900 & 1920 & 1867 & 1918 & 1843 & 1875 \\
\hline$S_{A_{h}}$ & 1859 & 1826 & 2008 & 1994 & 1881 & 1973 & 1828 & 1917 & 1947 & 1867 & 1895 & 1889 & 1911 \\
\hline \multicolumn{14}{|c|}{ Tb.N } \\
\hline$S_{A_{l}}$ & 10.41 & 10.81 & 12.58 & 12.49 & 10.94 & 11.28 & 10.95 & 11.67 & 12.21 & 11.37 & 11.61 & 11.29 & 11.52 \\
\hline$S_{A_{m}}$ & 11.30 & 11.54 & 11.27 & 11.35 & 11.68 & 11.14 & 11.38 & 11.47 & 11.55 & 11.61 & 11.24 & 11.46 & 11.65 \\
\hline$S_{A_{h}}$ & 12.75 & 12.11 & 10.61 & 10.62 & 11.84 & 12.04 & 12.13 & 11.32 & 10.70 & 11.48 & 11.61 & 11.71 & 11.29 \\
\hline \multicolumn{14}{|c|}{ Tb.Sp } \\
\hline$S_{A_{l}}$ & 7066 & 6400 & 4946 & 5092 & 6413 & 6552 & 6421 & 5824 & 5200 & 6019 & 5686 & 5971 & 5875 \\
\hline$S_{A_{m}}$ & 5651 & 5903 & 5904 & 5760 & 5769 & 5883 & 5982 & 5842 & 5938 & 5762 & 5934 & 5800 & 5808 \\
\hline$S_{A_{h}}$ & 4791 & 5205 & 6658 & 6656 & 5326 & 5073 & 5105 & 5842 & 6370 & 5727 & 5888 & 5737 & 5825 \\
\hline \multicolumn{14}{|c|}{ Analysis 2} \\
\hline \multicolumn{14}{|l|}{ BF } \\
\hline$S_{A_{l}}$ & 4.07 & 4.39 & 4.95 & 4.98 & 4.36 & 4.05 & 4.35 & 4.68 & 4.97 & 4.67 & 4.64 & 4.65 & 4.63 \\
\hline$S_{A_{m}}$ & 4.69 & 4.66 & 4.61 & 4.61 & 4.67 & 4.69 & 4.69 & 4.64 & 4.61 & 4.65 & 4.70 & 4.69 & 4.69 \\
\hline$S_{A_{h}}$ & 5.22 & 4.93 & 4.42 & 4.39 & 4.95 & 5.24 & 4.94 & 4.66 & 4.40 & 4.66 & 4.64 & 4.64 & 4.66 \\
\hline \multicolumn{14}{|c|}{ Tb.Th } \\
\hline$S_{A_{l}}$ & 2038 & 2120 & 2284 & 2275 & 2131 & 1926 & 2084 & 2205 & 2309 & 2170 & 2185 & 2165 & 2151 \\
\hline$S_{A_{m}}$ & 2137 & 2173 & 2104 & 2160 & 2144 & 2192 & 2201 & 2125 & 2117 & 2171 & 2228 & 2185 & 2152 \\
\hline$S_{A_{h}}$ & 2350 & 2232 & 2137 & 2090 & 2250 & 2407 & 2240 & 2195 & 2099 & 2184 & 2112 & 2175 & 2222 \\
\hline \multicolumn{14}{|c|}{ Tb.N } \\
\hline$S_{A_{l}}$ & 9.95 & 9.90 & 9.69 & 9.72 & 9.77 & 10.17 & 10.01 & 9.89 & 9.67 & 9.81 & 9.96 & 10.07 & 10.09 \\
\hline$S_{A_{m}}$ & 10.13 & 9.94 & 10.29 & 10.01 & 10.12 & 9.99 & 9.78 & 9.90 & 10.14 & 9.98 & 9.66 & 9.80 & 9.82 \\
\hline$S_{A_{h}}$ & 9.61 & 9.85 & 9.71 & 9.96 & 9.80 & 9.53 & 9.90 & 9.90 & 9.88 & 9.90 & 10.07 & 9.82 & 9.78 \\
\hline \multicolumn{14}{|c|}{ Tb.Sp } \\
\hline$S_{A_{l}}$ & 7616 & 7109 & 6312 & 6172 & 7192 & 7276 & 7073 & 6546 & 6381 & 6714 & 6760 & 6706 & 6705 \\
\hline$S_{A_{m}}$ & 6509 & 6696 & 6630 & 6712 & 6471 & 6690 & 6580 & 6735 & 6589 & 6596 & 6683 & 6537 & 6484 \\
\hline$S_{A_{h}}$ & 5877 & 6197 & 7060 & 7118 & 6339 & 6036 & 6349 & 6721 & 7032 & 6692 & 6559 & 6759 & 6813 \\
\hline
\end{tabular}

From this table, it can be seen whether an increase or a decrease in a certain model parameter has a positive or a negative effect on each of the structure parameters

separation, while $V_{\mathrm{cl}}, F_{\mathrm{res}}$, and $E_{b}$ are positively related to trabecular separation.

\subsubsection{Effects of model parameter variations on bone remodeling}

The same parameter variations that determine the variations in bone fraction during the development of a bone structure are also the most important determinants of bone fraction variations during remodeling. Increases in $F$ and $D$, and to a lesser extent $\tau, n$, and $\mu$, have a positive effect on bone fraction, while increases in $V_{\mathrm{cl}}, F_{\mathrm{res}}$, and $E_{b}$ have a negative effect on bone fraction.

However, it can be seen that these parameters exert their effect on bone fraction by different mechanisms in remodeling than in the first analysis. In remodeling, the most influential parameters with respect to trabecular thickness are $F$ and $D$, both of which are positively linearly related to trabecular thickness. Variation in $D$ had a similar effect in both analyses, but variations in $F$ did not have a major effect on trabecular 
Table 7 Sum of squares per model parameter expressed as percentage of the total sum of squares (combined, linear, and quadratic sum of squares)

\begin{tabular}{|c|c|c|c|c|c|c|c|c|c|c|c|c|c|}
\hline & $F$ & $\tau$ & $V_{\mathrm{cl}}$ & $F_{\text {res }}$ & $n$ & $D$ & $\mu$ & $k_{\mathrm{thr}}$ & $E_{b}$ & $v_{b}$ & $E_{m}$ & $v_{m}$ & $\gamma$ \\
\hline \multicolumn{14}{|c|}{ Analysis 1} \\
\hline \multicolumn{14}{|l|}{ BF } \\
\hline$S S_{A}$ & 33.1 & 7.9 & 5.1 & 6.2 & 5.1 & 27.1 & 6.0 & 0.1 & 8.7 & 0.1 & 0.3 & 0.1 & 0.3 \\
\hline$S S_{A, l}$ & 33.1 & 7.9 & 4.9 & 6.0 & 5.1 & 27.1 & 6.0 & 0.0 & 8.7 & 0.0 & 0.0 & 0.1 & 0.0 \\
\hline$S S_{A, q}$ & 0.0 & 0.0 & 0.2 & 0.3 & 0.0 & 0.0 & 0.0 & 0.1 & 0.0 & 0.0 & 0.3 & 0.0 & 0.3 \\
\hline \multicolumn{14}{|l|}{ Tb.Th } \\
\hline$S S_{A}$ & 2.5 & 6.3 & 30.2 & 17.0 & 1.4 & 18.1 & 5.6 & 1.0 & 7.5 & 4.0 & 0.8 & 5.1 & 0.6 \\
\hline$S S_{A, l}$ & 2.4 & 3.3 & 28.5 & 17.0 & 0.9 & 16.0 & 4.3 & 0.9 & 6.7 & 3.0 & 0.2 & 1.7 & 0.0 \\
\hline$S S_{A, q}$ & 0.0 & 2.9 & 1.8 & 0.0 & 0.5 & 2.1 & 1.3 & 0.0 & 0.8 & 1.0 & 0.6 & 3.4 & 0.5 \\
\hline \multicolumn{14}{|l|}{ Tb.N } \\
\hline$S S_{A}$ & 26.4 & 8.0 & 19.1 & 16.8 & 4.4 & 4.4 & 6.8 & 0.6 & 10.9 & 0.3 & 0.9 & 0.8 & 0.6 \\
\hline$S S_{A, l}$ & 25.9 & 8.0 & 18.4 & 16.6 & 3.8 & 2.7 & 6.6 & 0.6 & 10.8 & 0.1 & 0.0 & 0.8 & 0.3 \\
\hline$S S_{A, q}$ & 0.5 & 0.0 & 0.7 & 0.3 & 0.5 & 1.7 & 0.2 & 0.0 & 0.1 & 0.2 & 0.9 & 0.0 & 0.4 \\
\hline \multicolumn{14}{|l|}{ Tb.Sp } \\
\hline$S S_{A}$ & 27.9 & 7.6 & 15.5 & 13.0 & 6.3 & 11.6 & 9.5 & 0.0 & 7.4 & 0.5 & 0.4 & 0.3 & 0.0 \\
\hline$S S_{A, l}$ & 27.3 & 7.5 & 15.5 & 12.9 & 6.2 & 11.5 & 9.1 & 0.0 & 7.2 & 0.5 & 0.2 & 0.3 & 0.0 \\
\hline$S S_{A, q}$ & 0.5 & 0.1 & 0.1 & 0.1 & 0.1 & 0.0 & 0.3 & 0.0 & 0.2 & 0.1 & 0.2 & 0.0 & 0.0 \\
\hline \multicolumn{14}{|c|}{ Analysis 2} \\
\hline \multicolumn{14}{|l|}{ BF } \\
\hline$S S_{A}$ & 28.1 & 6.1 & 6.2 & 7.5 & 7.4 & 30.0 & 7.4 & 0.0 & 7.0 & 0.0 & 0.1 & 0.1 & 0.1 \\
\hline$S S_{A, l}$ & 28.0 & 6.2 & 5.9 & 7.4 & 7.4 & 30.0 & 7.4 & 0.0 & 6.9 & 0.0 & 0.0 & 0.0 & 0.0 \\
\hline$S S_{A, q}$ & 0.1 & 0.0 & 0.2 & 0.2 & 0.0 & 0.1 & 0.1 & 0.0 & 0.2 & 0.0 & 0.1 & 0.1 & 0.1 \\
\hline \multicolumn{14}{|l|}{ Tb.Th } \\
\hline$S S_{A}$ & 18.7 & 2.3 & 6.7 & 6.4 & 3.1 & 42.7 & 4.8 & 1.4 & 10.0 & 0.0 & 2.5 & 0.1 & 1.2 \\
\hline$S S_{A, l}$ & 17.9 & 2.3 & 4.0 & 6.3 & 2.6 & 42.5 & 4.5 & 0.0 & 8.1 & 0.0 & 1.0 & 0.0 & 0.9 \\
\hline$S S_{A, q}$ & 0.8 & 0.0 & 2.8 & 0.1 & 0.5 & 0.2 & 0.4 & 1.4 & 1.9 & 0.0 & 1.5 & 0.1 & 0.3 \\
\hline \multicolumn{14}{|l|}{ Tb.N } \\
\hline$S S_{A}$ & 13.1 & 0.4 & 21.9 & 4.5 & 7.1 & 20.5 & 2.5 & 0.0 & 10.4 & 1.4 & 8.5 & 4.3 & 5.4 \\
\hline$S S_{A, l}$ & 5.4 & 0.1 & 0.0 & 2.7 & 0.0 & 19.3 & 0.6 & 0.0 & 2.1 & 0.4 & 0.6 & 2.9 & 4.5 \\
\hline$S S_{A, q}$ & 7.7 & 0.3 & 21.9 & 1.8 & 7.1 & 1.2 & 1.9 & 0.0 & 8.4 & 1.0 & 7.9 & 1.3 & 0.8 \\
\hline \multicolumn{14}{|l|}{ Tb.Sp } \\
\hline$S S_{A}$ & 34.3 & 9.2 & 6.2 & 10.0 & 9.3 & 17.0 & 6.1 & 0.5 & 4.9 & 0.2 & 0.5 & 0.6 & 1.2 \\
\hline$S S_{A, l}$ & 33.5 & 9.2 & 6.2 & 9.9 & 8.1 & 17.0 & 5.8 & 0.3 & 4.7 & 0.0 & 0.4 & 0.0 & 0.1 \\
\hline$S S_{A, q}$ & 0.8 & 0.0 & 0.0 & 0.1 & 1.3 & 0.0 & 0.3 & 0.2 & 0.2 & 0.2 & 0.0 & 0.6 & 1.1 \\
\hline
\end{tabular}

$S S_{A}$ indicates the individual contribution of the variation in each model parameter to the variation in each structure parameter. $S S_{A, l}$ and $S S_{A, q}$ indicate the linearity of the relation between each model parameter and structure parameter. If a structure parameter is linearly related to a model parameter, $S S_{A, l}$ is equal to $S S_{A}$, and $S S_{A, q}$ is 0

thickness in the first analysis. Additionally, $V_{\mathrm{cl}}, F_{\text {res }}$ and $E_{b}$ are markedly negatively related to trabecular thickness in remodeling.

Trabecular number is mainly influenced by $V_{\mathrm{cl}}$ and $D$, which is also different from the first analysis. An increase in $D$ linearly decreases trabecular number, while both an increase and a decrease in $V_{\mathrm{cl}}$ decrease trabecular number compared to normal. An increase in $V_{\mathrm{cl}}$ decreases trabecular number through resorption of trabeculae, while a decrease in
$V_{\mathrm{cl}}$ decreases trabecular number through fusion of trabeculae. This quadratic effect is also dominant for other influential parameters such as $F, n, E_{b}$, and $E_{m}$. The linear effect of $D$ indicates that an increase in $D$ results in fusion of trabeculae, while a decrease counteracts negative effects of other parameters on trabecular number.

For trabecular separation, parameters have the opposite effect compared to their effect on bone fraction. The most influential parameters, $F$ and $D$, are both inversely 
Table 8 Qualitative effect of parameter variations on bone structure parameters
This table shows the effect that a decrease (-) and an increase (+) in each model parameter had on the bone structure parameters

\begin{tabular}{|c|c|c|c|c|c|c|c|c|c|}
\hline & & \multicolumn{4}{|c|}{ Analysis 1} & \multicolumn{4}{|c|}{ Analysis 2} \\
\hline & & $\mathrm{BF}$ & Tb.Th & Tb.N & $\mathrm{Tb} . \mathrm{Sp}$ & $\mathrm{BF}$ & Tb.Th & Tb.N & $\mathrm{Tb} . \mathrm{Sp}$ \\
\hline \multirow[t]{2}{*}{$F$} & - & $\downarrow \downarrow$ & $\sim$ & $\downarrow \downarrow$ & $\uparrow \uparrow$ & $\downarrow \downarrow$ & $\downarrow \downarrow$ & $\downarrow \downarrow$ & $\uparrow \uparrow$ \\
\hline & + & $\uparrow \uparrow$ & $\sim$ & $\uparrow \uparrow$ & $\downarrow \downarrow$ & $\uparrow \uparrow$ & $\uparrow \uparrow$ & $\downarrow \downarrow$ & $\downarrow \downarrow$ \\
\hline \multirow[t]{2}{*}{$\tau$} & - & $\downarrow$ & $\downarrow$ & $\downarrow$ & $\uparrow$ & $\downarrow$ & $\sim$ & $\sim$ & $\uparrow$ \\
\hline & + & $\uparrow$ & $\downarrow$ & $\uparrow$ & $\downarrow$ & $\uparrow$ & $\sim$ & $\sim$ & $\downarrow$ \\
\hline \multirow[t]{2}{*}{$V_{\mathrm{cl}}$} & - & $\uparrow \uparrow$ & $\downarrow \downarrow$ & $\uparrow \uparrow$ & $\downarrow \downarrow$ & $\uparrow$ & $\uparrow$ & $\downarrow \downarrow$ & $\downarrow$ \\
\hline & + & $\downarrow$ & $\uparrow$ & $\downarrow$ & $\uparrow \uparrow$ & $\downarrow$ & $\sim$ & $\downarrow \downarrow$ & $\uparrow$ \\
\hline \multirow[t]{2}{*}{$F_{\text {res }}$} & - & $\uparrow$ & $\downarrow \downarrow$ & $\uparrow \uparrow$ & $\downarrow \downarrow$ & $\uparrow$ & $\uparrow$ & $\sim$ & $\downarrow \downarrow$ \\
\hline & + & $\downarrow$ & $\uparrow \uparrow$ & $\downarrow \downarrow$ & $\uparrow \uparrow$ & $\downarrow$ & $\downarrow$ & $\sim$ & $\uparrow \uparrow$ \\
\hline \multirow[t]{2}{*}{$n$} & - & $\downarrow$ & $\sim$ & $\sim$ & $\uparrow$ & $\downarrow$ & $\sim$ & $\downarrow$ & $\uparrow$ \\
\hline & + & $\uparrow$ & $\sim$ & $\sim$ & $\downarrow$ & $\uparrow$ & $\sim$ & $\downarrow$ & $\downarrow$ \\
\hline \multirow[t]{2}{*}{$D$} & - & $\downarrow \downarrow$ & $\downarrow \downarrow$ & $\sim$ & $\uparrow$ & $\downarrow \downarrow$ & $\downarrow \downarrow$ & $\uparrow \uparrow$ & $\uparrow \uparrow$ \\
\hline & + & $\uparrow \uparrow$ & $\uparrow$ & $\sim$ & $\downarrow$ & $\uparrow \uparrow$ & $\uparrow \uparrow$ & $\downarrow \downarrow$ & $\downarrow \downarrow$ \\
\hline \multirow[t]{2}{*}{$\mu$} & - & $\downarrow$ & $\sim$ & $\downarrow$ & $\uparrow$ & $\downarrow$ & $\sim$ & $\sim$ & $\uparrow$ \\
\hline & + & $\uparrow$ & $\downarrow$ & $\uparrow$ & $\downarrow$ & $\uparrow$ & $\sim$ & $\sim$ & $\downarrow$ \\
\hline \multirow[t]{2}{*}{$k_{\mathrm{thr}}$} & - & $\sim$ & $\sim$ & $\sim$ & $\sim$ & $\sim$ & $\sim$ & $\sim$ & $\sim$ \\
\hline & + & $\sim$ & $\sim$ & $\sim$ & $\sim$ & $\sim$ & $\sim$ & $\sim$ & $\sim$ \\
\hline \multirow[t]{2}{*}{$E_{b}$} & - & $\uparrow$ & $\downarrow$ & $\uparrow \uparrow$ & $\downarrow$ & $\uparrow$ & $\uparrow \uparrow$ & $\downarrow \downarrow$ & $\sim$ \\
\hline & + & $\downarrow$ & $\uparrow$ & $\downarrow \downarrow$ & $\uparrow$ & $\downarrow$ & $\downarrow \downarrow$ & $\downarrow \downarrow$ & $\sim$ \\
\hline \multirow[t]{2}{*}{$v_{b}$} & - & $\sim$ & $\sim$ & $\sim$ & $\sim$ & $\sim$ & $\sim$ & $\sim$ & $\sim$ \\
\hline & + & $\sim$ & $\sim$ & $\sim$ & $\sim$ & $\sim$ & $\sim$ & $\sim$ & $\sim$ \\
\hline \multirow[t]{2}{*}{$E_{m}$} & - & $\sim$ & $\sim$ & $\sim$ & $\sim$ & $\sim$ & $\sim$ & $\uparrow$ & $\sim$ \\
\hline & + & $\sim$ & $\sim$ & $\sim$ & $\sim$ & $\sim$ & $\sim$ & $\uparrow$ & $\sim$ \\
\hline \multirow[t]{2}{*}{$v_{m}$} & - & $\sim$ & $\uparrow$ & $\sim$ & $\sim$ & $\sim$ & $\sim$ & $\sim$ & $\sim$ \\
\hline & + & $\sim$ & $\uparrow$ & $\sim$ & $\sim$ & $\sim$ & $\sim$ & $\sim$ & $\sim$ \\
\hline \multirow[t]{2}{*}{$\gamma$} & - & $\sim$ & $\sim$ & $\sim$ & $\sim$ & $\sim$ & $\sim$ & $\uparrow$ & $\sim$ \\
\hline & + & $\sim$ & $\sim$ & $\sim$ & $\sim$ & $\sim$ & $\sim$ & $\downarrow$ & $\sim$ \\
\hline
\end{tabular}

and linearly related to trabecular separation. Furthermore, increases in $V_{\mathrm{cl}}$ and $F_{\text {res }}$ increase trabecular separation, while increases in $\tau, n$, and $\mu$ decrease trabecular separation.

\section{Discussion}

The goal of this study was to investigate the sensitivity of the bone microarchitecture for four different factors; changes in mechanical load, changes in bone cellular activities, changes in mechanotransduction, and changes in mechanical tissue properties. We differentiated between the effect of these factors when they are already present during growth, and when they occur after the development of a mature trabecular structure. The main difference between these two analyses was that similar to in vivo bone adaptation (Frost 1999), no new trabeculae were formed during simulations of adaptation of an existing trabecular structure.

Changes in mechanical load were represented by changes in model parameter $F$, which had a marked effect on bone structure in both analyses. The simulations are in agreement with the effect of unloading in rats, which decreases bone fraction, trabecular thickness, and trabecular number, and increases trabecular separation (Laib et al. 2000). It has been known for a long time that decreased loading can induce bone loss, for example during disuse-related osteoporosis or space flight. In contrast, increased joint loading may play a role in the development of subchondral sclerosis in osteoarthritis. In osteoarthritic joints, bone fraction and trabecular thickness are frequently increased, while trabecular number and trabecular separation are decreased (Bobinac et al. 2003; Grynpas et al. 1991; Fazzalari and Parkinson 1998). This is in concurrence with our high load simulations.

Model parameters related to bone cellular activities are bone formation time constant $\tau$, resorption space $V_{\mathrm{cl}}$, resorption frequency $F_{\text {res }}$, and osteocyte density $n$. Although the effect for these individual parameters was not as marked as for the mechanical load, alterations in each changed the bone structure in both analyses. We predicted increases in bone fraction and trabecular thickness in response to an increase 
in $\tau$, which represents osteoblast activity. This is in agreement with the effect of prostaglandin E administration (Lin et al. 1994), which has been shown to block osteoblast apoptosis (Machwate et al. 1998). In contrast, a decrease in osteoblast activity seems to compromise the mechanical properties of the bone, indicating that this may play a role in bone degenerative processes. Variations in $F_{\text {res }}$ and $V_{\mathrm{cl}}$, representing the number of active osteoclasts and the osteoclast resorption area respectively, both had a similar influence on the bone structure, although the model was more sensitive for $V_{\mathrm{cl}}$. It is likely that the increases in both osteoclast number and osteoclast activity caused by estrogen deficiency (Henriksen et al. 2007) play an important role in postmenopausal osteoporosis. Similar to our simulations of increases in $F_{\text {res }}$ and $V_{\mathrm{cl}}$, estrogen deficiency decreased trabecular thickness and trabecular number, and increased trabecular separation in rats (Bagi et al. 1997). In the model, a decrease in osteocyte density negatively affected the bone architecture, because osteocytes promote osteoblastic bone formation in response to mechanical load. Decreases in osteocyte density have been reported for osteoporotic patients (Mullender et al. 2005), so this might indeed contribute to the bone loss observed in those patients. However, this is in conflict with a concurrent theory, which states that osteocytes inhibit osteoblastic bone formation in the absence of load (Martin 2000; van Bezooijen et al. 2004). In mice, killing 70-80\% of the osteocytes induced bone loss under ambulatory conditions (Tatsumi et al. 2007), similar to our simulations. However, in mice subjected to unloading, osteocyte ablation protected against bone loss (Tatsumi et al. 2007). This negative feedback mechanism is absent in our model, which means that under unloading conditions, the effect of a change in osteocyte number was not predicted correctly.

Model mechanotransduction parameters are osteocyte influence distance $D$, osteocyte mechanosensitivity $\mu$, and bone formation threshold $k_{\mathrm{thr}}$. A decrease in $D$ had a detrimental effect on bone architecture, indicating that blocking biochemical osteocyte signals could play an important role in bone diseases. In oculodentodigital dysplasia, osteocyte gap-junction connections are affected. But the skeletal abnormalities in this disease can not solely be attributed to blockage of biochemical osteocyte signals, since for example osteoblast differentiation is also affected (Civitelli 2008). With respect to $\mu$, our simulations show that when osteocytes become desensitized to mechanical loading, this may lead to deterioration in the bone architecture. Even in normal bone remodeling, desensitization is thought to occur after prolonged exposure to increased load (Schriefer et al. 2005). Possibly, pathologic conditions exist in which this desensitization is permanent. The predicted bone structure was not sensitive for changes in $k_{\mathrm{thr}}$, which represents the mechanical reference point for bone formation. Even in equilibrium, the osteocyte stimulus (locally) exceeded the formation threshold, resulting in basal bone formation that balances bone resorption. This indicates that the $15 \%$ variation of $k_{\mathrm{thr}}$ that we applied is relatively small compared to the difference between the osteocyte stimulus and formation threshold. If our simulations correctly represent in vivo bone remodeling, this means that a relatively small change in the sensitivity of osteoblasts for load-induced stimuli would not markedly affect bone architecture.

Mechanical tissue parameters included in the model are the elastic modulus and poisson ratio of both bone and bone marrow $\left(E_{b}, v_{b}, E_{m}\right.$ and $\left.v_{m}\right)$, and bone material parameter $\gamma$, which relates the bone elastic modulus to the bone volume fraction. The predicted bone structure was not sensitive to changes in $v_{b}$. Changes in $v_{m}$ only had a minor influence on trabecular thickness in the first analysis, and changes in $\gamma$ and $E_{m}$ only had a minor influence on trabecular number in the second analysis. In contrast, variations in the bone matrix stiffness did have a marked effect on bone architecture and may play a role in both osteoarthritis and osteogenesis imperfecta. Bone matrix stiffness is decreased in osteoarthritic joints (Day et al. 2001), and similar to our simulations, bone fraction and trabecular thickness are increased, while trabecular number and trabecular separation are decreased in osteoarthritic joints (Bobinac et al. 2003; Grynpas et al. 1991; Fazzalari and Parkinson 1998). In analogy with this, the changes in bone structure observed in osteogenesis imperfecta might be caused by an increase in bone matrix stiffness as a result of increased mineralization. In various forms of osteogenesis imperfecta, the bone fraction and trabecular thickness were increased, while trabecular number was decreased (Rauch et al. 2000), similar to our predicted effect of an increase in matrix stiffness during bone adaptation.

In the model, it is assumed that osteocytes can sense an SED equivalent loading measure and that they can stimulate osteoblast cells in their vicinity. Although these are assumptions, we have demonstrated in earlier studies that this model can explain a large number of trabecular bone features (Ruimerman et al. 2001) and that its results are not strongly dependent on the choice of the exact load parameter sensed by the osteocytes (Ruimerman et al. 2005) or even the assumed regulation mechanism (van Oers et al. 2010). In the present study, we used a 2D model, which limits the structures that can be represented. However, the aim was to investigate changes in bone architecture rather than to predict realistic trabecular structures, and the predicted changes in bone architecture seem to be in agreement with the in vivo remodeling response.

A strong point of our sensitivity analysis approach is that it can identify the importance of different factors in multi-factorial bone diseases. For example, it is known that Paget's disease is associated with increased osteoclast numbers and osteoclast activity (Ralston et al. 2008). This would be expected to decrease bone fraction and trabecular 
thickness, but instead these parameters seem increased in bone affected by Paget's disease. This may be explained by the decrease in bone matrix stiffness that is observed in $\mathrm{Pa}-$ get's disease, because this would result in a counteracting effect according to our simulations.

In conclusion, we found that alterations in mechanical load, bone cellular activities, mechanotransduction, and mechanical tissue properties may all affect bone architecture and play a role in various degenerative processes. Our predicted changes in bone architecture seem to be in agreement with the in vivo remodeling response, which makes the model a useful tool for the investigation into bone diseases and therapies. In particular, our simulations may help in gaining a better understanding of the contribution of individual disturbances to a complicated multi-factorial disease process.

Open Access This article is distributed under the terms of the Creative Commons Attribution Noncommercial License which permits any noncommercial use, distribution, and reproduction in any medium, provided the original author(s) and source are credited.

\section{References}

Akhter MP, Lappe JM, Davies KM, Recker RR (2007) Transmenopausal changes in the trabecular bone structure. Bone 41(1):111-116

Ashman RB, Cowin SC, Buskirk WCV, Rice JC (1984) A continuous wave technique for the measurement of the elastic properties of cortical bone. J Biomech 17(5):349-361

Bagi CM, Ammann P, Rizzoli R, Miller SC (1997) Effect of estrogen deficiency on cancellous and cortical bone structure and strength of the femoral neck in rats. Calcif Tissue Int 61(4):336-344

Bobinac D, Spanjol J, Zoricic S, Maric I (2003) Changes in articular cartilage and subchondral bone histomorphometry in osteoarthritic knee joints in humans. Bone 32(3):284-290

Bonewald LF (2006) Mechanosensation and transduction in osteocytes. Bonekey Osteovision 3(10):7-15

Choi K, Kuhn JL, Ciarelli MJ, Goldstein SA (1990) The elastic moduli of human subchondral, trabecular, and cortical bone tissue and the size-dependency of cortical bone modulus. J Biomech 23(11):1103-1113

Civitelli R (2008) Cell-cell communication in the osteoblast/osteocyte lineage. Arch Biochem Biophys 473(2):188-192

Cortet B, Chappard D, Boutry N, Dubois P, Cotten A, Marchandise X (2004) Relationship between computed tomographic image analysis and histomorphometry for microarchitectural characterization of human calcaneus. Calcif Tissue Int 75(1):23-31

Cowin SC, Moss-Salentijn L, Moss ML (1991) Candidates for the mechanosensory system in bone. J Biomech Eng 113(2):191-197

Currey JD (1988) The effect of porosity and mineral content on the young's modulus of elasticity of compact bone. J Biomech 21(2):131-139

Day JS, Ding M, Linden JCVD, Hvid I, Sumner DR, Weinans H (2001) A decreased subchondral trabecular bone tissue elastic modulus is associated with pre-arthritic cartilage damage. J Orthop Res 19(5):914-918

Eriksen EF, Kassem M (1992) The cellular basis of bone remodeling. Triangle 31(2):45-57
Fazzalari NL, Parkinson IH (1998) Femoral trabecular bone of osteoarthritic and normal subjects in an age and sex matched group. Osteoarthritis Cartilage 6(6):377-382

Frost HM (1999) On the trabecular "thickness"-number problem. J Bone Miner Res 14(11):1816-1821

Grynpas MD, Alpert B, Katz I, Lieberman I, Pritzker KP (1991) Subchondral bone in osteoarthritis. Calcif Tissue Int 49(1): 20-26

Han ZH, Palnitkar S, Rao DS, Nelson D, Parfitt AM (1997) Effects of ethnicity and age or menopause on the remodeling and turnover of iliac bone: implications for mechanisms of bone loss. J Bone Miner Res 12(4):498-508

Heijink A, Zobitz ME, Nuyts R, Morrey BF, An KN (2008) Prosthesis design and stress profile after hip resurfacing: a finite element analysis. J Orthop Surg (Hong Kong) 16(3):326-332

Henriksen K, Tanko LB, Qvist P, Delmas PD, Christiansen C, Karsdal MA (2007) Assessment of osteoclast number and function: application in the development of new and improved treatment modalities for bone diseases. Osteoporos Int 18(5):681-685

Hildebrand T, Laib A, Muller R, Dequeker J, Ruegsegger P (1999) Direct three-dimensional morphometric analysis of human cancellous bone: microstructural data from spine, femur, iliac crest, and calcaneus. J Bone Miner Res 14(7):1167-1174

Huiskes R, Ruimerman R, van Lenthe GH, Janssen JD (2000) Effects of mechanical forces on maintenance and adaptation of form in trabecular bone. Nature 405(6787):704-706

Jonkers I, Sauwen N, Lenaerts G, Mulier M, der PGV, Jaecques S (2008) Relation between subject-specific hip joint loading, stress distribution in the proximal femur and bone mineral density changes after total hip replacement. J Biomech 41(16):34053413

Klein-Nulend J, van der PA, Semeins CM, Ajubi NE, Frangos JA, Nijweide PJ, Burger EH (1995) Sensitivity of osteocytes to biomechanical stress in vitro. FASEB J 9(5):441-445

Klein-Nulend J, Nijweide PJ, Burger EH (2003) Osteocyte and bone structure. Curr Osteoporos Rep 1(1):5-10

Krug R, Carballido-Gamio J, Burghardt AJ, Kazakia G, Hyun BH, Jobke B, Banerjee S, Huber M, Link TM, Majumdar S (2008) Assessment of trabecular bone structure comparing magnetic resonance imaging at 3 tesla with high-resolution peripheral quantitative computed tomography ex vivo and in vivo. Osteoporos Int 19(5):653-661

Laib A, Barou O, Vico L, Lafage-Proust MH, Alexandre C, Rugsegger $\mathrm{P}$ (2000) 3d micro-computed tomography of trabecular and cortical bone architecture with application to a rat model of immobilisation osteoporosis. Med Biol Eng Comput 38(3):326-332

Lanyon LE (1993) Osteocytes, strain detection, bone modeling and remodeling. Calcif Tissue Int 53(Suppl 1):S102-S106

Lin BY, Jee WS, Ma YF, Ke HZ, Kimmel DB, Li XJ (1994) Effects of prostaglandin e 2 and risedronate administration on cancellous bone in older female rats. Bone 15(5):489-496

Liu XS, Sajda P, Saha PK, Wehrli FW, Guo XE (2006) Quantification of the roles of trabecular microarchitecture and trabecular type in determining the elastic modulus of human trabecular bone. J Bone Miner Res 21(10): 1608-1617

Logothetis N, Wynn HP (1989) Quality through design. Experimental design, off-line quality control, and Taguchi's contributions. Oxford Scientific Publications, Oxford University Press, Oxford

Machwate M, Rodan SB, Rodan GA, Harada SI (1998) Sphingosine kinase mediates cyclic amp suppression of apoptosis in rat periosteal cells. Mol Pharmacol 54(1):70-77

Marotti G, Cane V, Palazzini S, Palumbo C (1990) Structurefunction relationships in the osteocyte. Ital J Miner Electrolyte Metab 4(2):93-106

Martin RB (2000) Does osteocyte formation cause the nonlinear refilling of osteons? Bone 26(1):71-78 
Mullender M, Haj AJE, Yang Y, van Duin MA, Burger EH, Klein-Nulend J (2004) Mechanotransduction of bone cells in vitro: mechanobiology of bone tissue. Med Biol Eng Comput 42(1):14-21

Mullender MG, Huiskes R (1995) Proposal for the regulatory mechanism of wolff's law. J Orthop Res 13(4):503-512

Mullender MG, Tan SD, Vico L, Alexandre C, Klein-Nulend J (2005) Differences in osteocyte density and bone histo-morphometry between men and women and between healthy and osteoporotic subjects. Calcif Tissue Int 77(5):291-296

Parfitt AM (1994) Osteonal and hemi-osteonal remodeling: the spatial and temporal framework for signal traffic in adult human bone. J Cell Biochem 55(3):273-286

Ralston SH, Langston AL, Reid IR (2008) Pathogenesis and management of paget's disease of bone. Lancet 372(9633):155-163

Rauch F, Travers R, Parfitt AM, Glorieux FH (2000) Static and dynamic bone histomorphometry in children with osteogenesis imperfecta. Bone 26(6):581-589

Rho JY (1996) An ultrasonic method for measuring the elastic properties of human tibial cortical and cancellous bone. Ultrasonics 34(8):777-783

Rho JY, Ashman RB, Turner CH (1993) Young's modulus of trabecular and cortical bone material: ultrasonic and microtensile measurements. J Biomech 26(2):111-119

Ruimerman R, Huiskes R, van Lenthe GH, Janssen JD (2001) A computer-simulation model relating bone-cell metabolism to mechanical adaptation of trabecular architecture. Comput Methods Biomech Biomed Eng 4(5):433-448

Ruimerman R, van Rietbergen B, Hilbers P, Huiskes R (2005) The effects of trabecular-bone loading variables on the surface signaling potential for bone remodeling and adaptation. Ann Biomed Eng 33(1):71-78

Schriefer JL, Warden SJ, Saxon LK, Robling AG, Turner CH (2005) Cellular accommodation and the response of bone to mechanical loading. J Biomech 38(9):1838-1845

Tatsumi S, Ishii K, Amizuka N, Li M, Kobayashi T, Kohno K, Ito M, Takeshita S, Ikeda K (2007) Targeted ablation of osteocytes induces osteoporosis with defective mechanotransduction. Cell Metab 5(6):464-475

van Bezooijen RL, Roelen BA, Visser A, van der Wee-Pals L, de Wilt E, Karperien M, Hamersma H, Papapoulos SE, ten Dijke P, Lowik CW (2004) Sclerostin is an osteocyte-expressed negative regulator of bone formation, but not a classical bmp antagonist. J Exp Med 199(6):805-814

van Oers RFM, van Rietbergen B, Hilbers P, K Ito RH (2010) A sclerostin-based theory for strain-induced bone formation. European Conference on Computational Mechanics

van Rietbergen B, Weinans H, Huiskes R, Odgaard A (1995) A new method to determine trabecular bone elastic properties and loading using micromechanical finite-element models. J Biomech 28(1):69-81 